Coleção TSC em Debate

Volume I

\title{
Autoeficácia em Contextos de Saúde, Educação e Política
}

Roberto Tadeu laochite

Roberta Gurgel Azzi

Organizadores 
๑) 2017 - Autores

\section{Revisão}

Ellen Garber

\section{Projeto gráfico}

Ronaldo Machado | Letra1

\section{Impressão}

Printstore

DADOS INTERNACIONAIS DE PUBLICAÇÃO Bibliotecária Ketlen Stueber CRB: 10/2221

Autoeficácia em contextos de saúde, educação e política / organização de Roberto Tadeu Iaochite e Roberta Gurgel Azzi . - Porto Alegre : Letra1, 2017. (Coleção TSC em Debate; 1) 142 p.

ISBN 978-85-63800-29-9

DOI 10.21826/9788563800299

1. Teoria Social Cognitiva. 2. Construto da autoefi cácia. 3. Efi cácia pessoal. I. Iaochite, Roberto Tadeu. II. Azzi, Roberta Gurgel. III. Título. IV. Série.

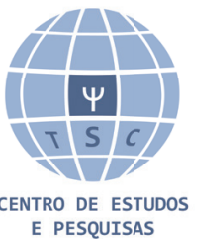

RUA FELIPE SIQUEIRA, 33

BRAGANÇA PAULISTA - SP

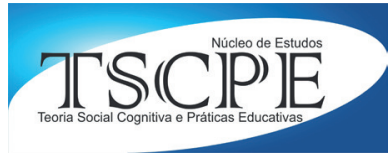

UNIVERSIDADE ESTADUAL PAULISTA

"JÚLIO DE MESQUITA FILHO"

IB - DEPARTAMENTO DE EDUCAÇÃO

RIO CLARO - SP

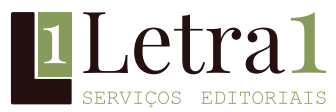

www.editoraletra1.com.br

CNPJ 12.062.268/0001-37

PORTO ALEGRE - RS 


\section{Conselho Editorial}

\section{Acácia Aparecida Angeli dos Santos}

Universidade São Francisco

Altemir José Gonçalves Barbosa

Universidade Federal de Juiz de Fora

\section{Diana Santiago}

Universidade Federal da Bahia

\section{José Aloyseo Bzuneck}

Universidade Estadual de Londrina

Jussara Cristina Barboza Tortella

Pontifícia Universidade Católica de Campinas

Katia Regina Xavier da Silva

Colégio Pedro II

Universidade do Estado de Rio de Janeiro

Maria do Carmo Guedes

Pontifícia Universidade Católica de São Paulo

Soely Aparecida Jorge Polydoro

Universidade Estadual de Campinas 


\section{SUMÁRIO}

Apresentação

Capítulo 1

Crenças de Autoeficácia: considerações teóricas

Roberto Tadeu laochite

Capítulo 2

Autoeficácia em Contexto de Saúde:

achados da literatura brasileira

Luiza Cristina Mauad Ferreira e Roberta Gurgel Azzi

Capítulo 3

Investigações e Práticas em Escolas Promotoras de Saúde:

aproximações com a Teoria Social Cognitiva

Roberto Tadeu laochite

\section{Capítulo 4}

Formação Inicial de Professores e Crenças de Autoeficácia para Ensinar Educação Física na Escola

Roraima Alves da Costa Filho e Roberto Tadeu laochite

\section{Capítulo 5}

Crenças de Autoeficácia Docente Robustas: estratégias para prevenir o desenvolvimento da Síndrome de Burnout Luiza Cristina Mauad Ferreira

\section{Capítulo 6}

Crença de Autoeficácia para Prática de Atividade Física e Variáveis de Contexto de uma Escola Pública Paulista

Roberto Tadeu Iaochite e Roraima Alves da Costa Filho 


\section{Capítulo 7}

Autoeficácia e Autorregulação: interfaces no âmbito da escrita

Soely Aparecida Jorge Polydoro

e Eduarla Resende Videira Emílio

\section{Capítulo 8}

Autoeficácia e Participação Política

Guilherme Azzi Russo

Sobre os autores 
Coleção TSC em Debate

Volume I

\section{Autoeficácia em Contextos de Saúde, Educação e Política}




\section{Apresentação}

O interesse pelos estudos sobre a crença de eficácia pessoal - autoeficácia - foi o motivo que, no início da década de 2000, aproximou os organizadores desta obra. Desde então, continuam estudando e produzindo conhecimento a respeito deste constructo postulado por Bandura em 1977. Outros autores, cujos conhecimentos e esforços se somam ao nosso nesta obra, oferecem imensa contribuição ao estudo de crenças de eficácia - estudos que, a cada dia, ganham novos adeptos, contextos, e novas explorações metodológicas de investigação e áreas de conhecimento.

As crenças de eficácia, como revela Bandura em sua obra Self-efficacy: The Exercise of Control, publicada há vinte anos, são o coração da agência humana. Ou seja, elas contribuem para a decisão das pessoas em se engajar em comportamentos que objetivam realizar, permanecer ou não se compromissar frente às dificuldades, e em se sentir bem durante sua execução. Esses são alguns dos recortes que se desenham ao se analisar o comportamento humano considerando o que as pessoas acreditam que podem fazer em direção a determinados objetivos.É sob a perspectiva conceitual da Teoria Social Cognitiva, em especial, o construto da autoeficácia proposto por Albert Bandura, que os textos que integram este livro discutem diferentes domínios, como ensino de educação física, saúde do professor, ensino da escrita e exercício político; e trazem contribuições fundamentadas nos postulados de Bandura sobre a crença de eficácia pessoal.

O leitor encontrará recortes interessantes nos capítulos desta obra, os quais problematizam o constructo da autoeficácia inserido em produções da literatura no contexto da saúde e na promoção de hábitos saudáveis na escola, além de discutir o papel desta crença no âmbito da formação inicial em Educação Física, no ensino da escrita e da política.

O primeiro capítulo "Crenças de autoeficácia - considerações teóricas”, escrito pelo professor Roberto Tadeu Iaochite, objetiva apresentar de forma abreviada os postulados de Bandura que fundamentam a autoeficácia quanto ao seu papel no comportamento humano. 
O capítulo a seguir intitula-se "Autoeficácia em contexto de saúde: achados na literatura brasileira", escrito pelas professoras Luiza Cristina Mauad Ferreira e Roberta Gurgel Azzi; reúne um conjunto de estudos em diversos contextos da saúde, e apresenta os principais resultados, enfatizando como se relacionam com a autoeficácia.

O terceiro capítulo, também escrito por Roberto Tadeu Iaochite, traz o conceito de escolas promotoras de saúde, apontando possíveis relações entre o desenvolvimento de uma escola saudável à luz dos postulados de Bandura, em especial sobre a relevância da autoeficácia nesse processo. O capítulo é intitulado "Investigações e práticas em escolas promotoras de saúde: aproximações com a autoeficácia”.

O quarto capítulo, intitulado "Formação inicial de professores e crenças de autoeficácia para ensinar Educação Física na escola”, é fruto do programa PIBID/ CAPES, desenvolvido com estudantes do curso de Licenciatura em Educação Física da Unesp, Rio Claro. Nesse projeto e no capítulo aqui apresentado, os professores Roraima Alves da Costa Filho e Roberto Tadeu Iaochite apresentam um dos estudos gerados da realização desse projeto, realçando a autoeficácia e suas fontes de construção para que futuros professores ensinem Educação Física na escola.

O quinto capítulo, escrito pela professora Luiza Cristina Mauad Ferreira, discute as crenças de autoeficácia do professor e as relações com o desenvolvimento da síndrome do Burnout. Estudos têm demonstrado que professores com elevado nível de autoeficácia para ensinar têm menores chances de serem acometidos pelo adoecimento gerado por essa síndrome.

Como forma de retratar os efeitos do Programa PIBID/CAPES comentado no quarto capítulo, Iaochite e Costa Filho apresentam, no sexto capítulo, os resultados de um estudo realizado com estudantes do ensino fundamental de uma das escolas participantes do projeto citado. $\mathrm{O}$ foco do estudo visava buscar relações entre a crença de autoeficácia e a possibilidade de os estudantes praticarem atividade física fora da escola como uma forma de incorporar o aprendizado do projeto, que versa sobre hábitos saudáveis na escola.

Entre os constructos que integram a teoria postulada por Bandura, a autorregulação é o mecanismo que ocupa papel fundamental no funcionamento humano. O sétimo capítulo, escrito pelas professoras Soely Aparecida Jorge Polydoro e Eduarla Resende Videira Emílio, discute as relações entre a autoeficácia e a autorregulação no processo de escrita.

Finalmente, o oitavo capítulo, escrito pelo cientista político Guilherme Azzi Russo, contribui com a discussão sobre o exercício da participação política e suas relações com a autoeficácia para que se possa agir nesse domínio. O capítulo é intitulado "Autoeficácia e participação política". 
Esperamos que essa coleção, e em especial esse volume, possa suscitar reflexões, questionamentos e o desejo de participar conosco nessa jornada composta pelos desafios de apresentar, qualificar e disseminar as ideias de Bandura no cenário brasileiro.

A jornada é longa, intensa, desafiadora e não menos, prazerosa! Como disse Bandura em diversos de seus textos que explicam as relações entre a Teoria Social Cognitiva, em especial, o papel da autoeficácia, "Que a força autoeficácia esteja com vocês", ou dito de outra forma: "Que a força da autoeficácia esteja conosco"!

Boa leitura!

Roberta Gurgel Azzi

Roberto Tadeu laochite

Organizadores 
Autoeficácia em Contextos de Saúde, Educação e Política

Roberto Tadeu laochite \& Roberta Gurgel Azzi

Organizadores

para continuar lendo, clique aqui 